\title{
Speculative Non-Fundamental Components in Mature Stock Markets: Do They Exist and Are They Related?
}

\author{
A. (Tassos) G. Malliaris \\ Loyola University Chicago, tmallia@luc.edu \\ Ramaprasad Bhar \\ The University of New South Wales
}

Follow this and additional works at: https://ecommons.luc.edu/business_facpubs

Part of the Business Commons

\section{Recommended Citation}

Malliaris, A. (Tassos) G. and Bhar, Ramaprasad. Speculative Non-Fundamental Components in Mature Stock Markets: Do They Exist and Are They Related?. Advances in Quantitative Analysis of Finance and Accounting, 3, : 217-246, 2006. Retrieved from Loyola eCommons, School of Business: Faculty Publications and Other Works,

This Article is brought to you for free and open access by the Faculty Publications and Other Works by Department at Loyola eCommons. It has been accepted for inclusion in School of Business: Faculty Publications and Other Works by an authorized administrator of Loyola eCommons. For more information, please contact ecommons@luc.edu.

\section{(c) $($ () $\ominus$}

This work is licensed under a Creative Commons Attribution-Noncommercial-No Derivative Works 3.0 License. (c) World Scientific, 2006. 


\title{
Speculative Nonfundamental Components in Mature Stock Markets: Do they Exist and are they Related?
}

\author{
Ramaprasad Bhar \\ School of Banking and Finance, \\ The University of New South Wales, Australia
}

\author{
A. G. Malliaris \\ Department of Economics and Finance, \\ Loyola University of Chicago, USA
}

Economists have long conjectured that movements in stock prices may involve speculative components, called bubbles. A bubble is defined as the difference between the market value of a security and its fundamental value. The topic of asset bubbles remains controversial because the existence of a bubble is inherently an empirical issue and no satisfactory test has yet been devised to estimate the magnitude of a bubble. This paper proposes a new methodology for testing for the existence of rational bubbles. Unlike previous authors, we treat both the dividend that drives the fundamental part and the nonfundamental process as part of the state vector. This new methodology is applied to the four mature markets of the US, Japan, England, and Germany to test whether a speculative component was present during the period of January 1951 to December 1998 in these markets. The paper also examines whether there are linkages between these national speculative components. We find evidence that the nonfundamental component in the US market causes the other three markets but we find no evidence for reverse causality.

Keywords: Kalman filter; mature stock markets; speculative bubbles.

\section{Introduction}

Campbell (2000) concludes that many economists accept market efficiency as the well-established paradigm of finance but also acknowledge that asset prices are too volatile. For example, NASDAQ, from its peak on March 10, 2000 when it stood at 5,048.62 to its low of 1,454.04 on September 21, 2001, declined by $71.25 \%$. Is this significant decline caused only because of substantial revisions of the market fundamentals or can it be viewed as the bursting of a speculative bubble?

The literature on bubbles or speculative components follows two broad methodologies: speculative components are assumed to be rational or irrational. 
The rational bubble approach is presented in Blanchard and Fisher (1989) who argue that in solving the difference equation that arises from asset price arbitrage conditions, the efficient market solution is not unique. There is also a rational bubble solution with asset prices deviating from fundamentals and expected to grow at the rate of return of the riskless asset. In contrast to the rational bubble approach, Keynes (1936) postulated the "irrational bubble" approach where asset prices are driven by "animal spirits". In this paper, we only consider "rational bubbles" and use the terms "rational bubble" and "speculative nonfundamental component" interchangeably.

This paper modifies certain empirical methodologies to test for the presence of rational bubbles and then explores the relationship among these bubbles in mature stock markets. Section 2 introduces general ideas about asset bubbles. In Section 3, we motivate our empirical methodology by reviewing the important contributions of $\mathrm{Wu}(1995,1997)$ and other econometricians. Section 4 examines global stock market integration and Section 5 highlights our new methodology for testing for the existence of asset bubbles and then applies it to the stock markets of the US, Japan, England, and Germany. We find evidence of asset bubbles in all four stock markets. We then proceed to examine whether these bubbles travel across mature economies. Our main findings and conclusions are given in the last section.

\section{Rational Asset Bubbles}

The standard definition of the fundamental value of an asset is the summed discounted value of all future cash flows generated by such an asset. The difference, if any, between the market value of the security and its fundamental value is termed a speculative bubble. The existence of bubbles is inherently an empirical issue that has not been settled. A number of studies such as Blanchard and Watson (1982) and West (1988) have argued that dividend and stock price data are not consistent with the "market fundamentals" hypothesis, in which prices are given by the present discounted values of expected dividends. These results have often been construed as evidence for the existence of bubbles or fads.

In addition, Shiller (1981) and LeRoy and Porter (1981) have argued that the variability of stock price movements is too large to be explained by the discounted present value of future dividends. Over the past century US stock prices are 5-13 times more volatile than can be justified by new information about future dividends. Campbell and Shiller (1988a, b) and West $(1987,1988)$ 
remove the assumption of a constant discount rate. However, a variable discount rate provides only marginal support in explaining stock price volatility. These authors reject the null hypothesis of no bubbles.

$\mathrm{Wu}$ (1997) examines a rational bubble, able to burst and restart continuously. The specification is parsimonious and allows easy estimation. The model fits the data reasonably well, especially during several bull and bear markets in this century. Such rational bubbles can explain much of the deviation of US stock prices from the simple present-value model. Wu's work is reviewed in more detail in the next section. Beyond the existence or not of bubbles, economists have also studied in detail the implications of a stock market bubble to the economy at large. Binswanger (1999) offers a comprehensive review of these issues and Chirinko and Schaller (1996) argue that bubbles have existed over certain periods in the US stock market but real investment decisions have been determined by fundamentals. Hayford and Malliaris (2001) argue that easy monetary policy may have contributed to the US stock market bubble during 1995-2000.

\section{Review of Key Empirical Papers}

To motivate our methodological contribution to testing for asset bubbles, we examine few influential papers in this area.

\subsection{Flood and Garber (1980)}

Flood and Garber (1980) test the hypothesis that price-level bubbles did not exist in a particular historical period. The existence of a price-level bubble places such extraordinary restrictions on the data that such bubbles are not an interesting research problem during normal times. Since hyperinflations generated series of data extraordinary enough to admit the existence of a pricelevel bubble, the German episode is an appropriate and interesting period to search for bubbles. The authors build a theoretical model of hyperinflation in which they allow price-level bubbles. Then, they translate the theoretical model into data restrictions and use these restrictions to test the hypothesis that price-level bubbles were not partly responsible for Germany's massive inflation during the early 1920s.

Cagan (1956) used the following monetary model in his study of seven hyperinflations:

$$
m_{t}-p_{t}=y+\alpha \pi_{t}+\varepsilon_{t}, \quad \alpha<0, \quad t=1,2,3, \ldots .
$$


The variables $m$ and $p$ are the natural logarithms of money and price at time $t$. The anticipated rate of inflation between $t$ and $t+1$ is $\pi$ and $\varepsilon$ is a stochastic disturbance term. The rational-expectations assumption requires $\pi_{t}=E\left(\pi_{t} \mid I_{t}\right)$, where $\pi_{t}=p_{t+1}-p_{t}$ is the mathematical expectations operator, and $I$ is the information set available for use at time $t$.

The solution of Equation (1) is

$$
p_{t}=-\alpha A_{0} \psi^{t}+\left[m_{t}-y+\psi^{-1} \sum E\left(\psi_{t+1}-w_{t+i} I I_{t}\right) \psi^{-1}-\varepsilon_{t}\right],
$$

where $\psi \equiv(\alpha-1) / \alpha>1, \mu_{t+i}=m_{t+i+1}-m_{t+i}, w_{t+i}=\varepsilon_{t+i+1}-\varepsilon_{t+i}$ and $A$ is an arbitrary constant.

For this model, market fundamentals are defined as

$$
\left[m_{t}-y+\psi^{-1} \sum E\left(\psi_{t+1}-w_{t+i} I I_{t}\right) \psi^{-1}-\varepsilon_{t}\right],
$$

price-level bubbles are then captured by the term $-\alpha A_{0} \psi^{t}$.

Rational-expectations models normally contain the assumption $A=0$, which prevents bubbles. Notice that if $A \neq 0$, then the price will change with $t$ even if market fundamentals are constant. The definition of a price-level bubble as a situation in which $A \neq 0$ is appropriate for two reasons. First, $A$ is an arbitrary and self-fulfilling element in expectations. Second, if $A \neq 0$, then agents expect prices to change through time at an ever-accelerating rate, even if market fundamentals do not change. Since economists usually consider price bubbles to be episodes of explosive price movement that are unexplained by the normal determinants of market price, $A \neq 0$ will produce a price-level bubble. The results of the empirical analysis presented by Flood and Garber support the hypothesis of no price-level bubbles.

\subsection{West (1987)}

The test compares two sets of estimates of the parameters needed to calculate the expected present discounted value (PDV) of a given stock's dividend stream, with expectations conditional on current and all past dividends. In a constant discount rate model the two sets are obtained as follows. One set is obtained by regressing the stock price on a suitable set of lagged dividends. The other set is obtained indirectly from a pair of equations. One is an arbitrage equation yielding the discount rate, and the other is the ARIMA equation of the dividend process.

Under the null hypothesis that the stock price is set in accord with a standard efficient markets model, the regression coefficients in all equations may be estimated consistently. When the two sets of estimates of the expected PDV 
parameters are compared, then, they should be the same, apart from sampling error. This equality will not hold under the alternative hypothesis that the stock price equals the sum of two components: the price implied by the efficient markets model and a speculative bubble.

A stock price is determined by the arbitrage condition:

$$
p_{t}=b E\left(p_{t+1}+d_{t+1}\right) \mid I_{t},
$$

where $p$ is the real stock price in period $t, b$ the constant ex ante real discount rate, $0<b=1 /(1+r)<1, r$ the constant expected return, $E$ is mathematical expectation, $d$ is the real dividend paid in period $t+1$, and $I$ denotes information common to traders at period $t$.

As long as the transversality condition $\lim _{n \rightarrow \infty} b^{n} E\left[p_{t+n} \mid I_{t}\right]=0$ holds, the unique forward solution to Equation (1) is $p_{t}^{*} \sum b^{i} E\left[d_{t+i} \mid I_{t}\right]$. If this condition fails, there is a family of solutions to Equation (2). Any $p$ that satisfies $p_{t}=$ $p_{t}^{*}+c_{t}, E\left[c_{t} \mid I_{t-1}\right]=b^{-1} c_{t-1}$ is also a solution. $c$ is by definition a speculative bubble. The aim of West is to test $p_{t}=p_{t}^{*}$, versus $p_{t}=p_{t}^{*}+c$.

Checking for the equality of the two sets in long-term annual data on the Standard and Poor's 500 Index (1871-1980) and the Dow Jones Index (19281978), the author finds that the null hypothesis of no bubbles is rejected and the coefficients in the regression of price on dividends are biased upwards.

\subsection{Ikeda and Shibata (1992)}

Using a stochastic dividend-growth model, the paper provides a general analysis of fundamental-dependent bubbles in stock prices. Given that dividends follow a continuous Markov process, a stock price is specified as a function of dividends as well as of time. The authors derive a partial differential equation with respect to this price function from an arbitrage equation. Provided that a free-disposal condition is satisfied, a fundamental price process is defined as the forward-looking particular solution of this equation and a price bubble as the general solution of the corresponding homogeneous equation.

Consider a stock share that yields dividends $D(t)$ at time $t$. These dividends follow a geometric Brownian motion with positive drift:

$$
\begin{aligned}
\mathrm{d} D(t) & =g D(t) \mathrm{d} t+\sigma D(t) \mathrm{d} z(t), \\
D(0) & =D_{0}, \quad g-\sigma^{2} / 2>0, \quad \sigma>0 .
\end{aligned}
$$

The constants $g$ and $\sigma$ are, respectively, the expected value and the standard deviation of the instantaneous rate of dividend growth. $\mathrm{d} z$ is an independent 
increment of a standard Wiener process, $z$, with the initial condition $z(0)=0$. Since $\ln D$ follows a normal distribution, the time series of dividend payments have a positive trend.

The stochastic dividend-payment process described in Equation (3) is the only source of randomness. Assume risk neutrality of investors, free disposability of the stock and also that the cum-dividend stock price is determined by the following two conditions:

$$
\begin{gathered}
E\left[\mathrm{~d} P(t) \mid \Omega_{t}\right] / \mathrm{d} t+D(t)=r P(t), \\
P(t) \geq 0, \quad \text { with } r>0 \quad \forall t \in[0, \infty] \text { w.p. } 1,
\end{gathered}
$$

where, $E\left[\cdot \mid \Omega_{t}\right]$ represents mathematical expectations conditional on $\Omega$, and parameter $r$ denotes the constant riskless interest rate.

The rational expectations stochastic process of the stock price is obtained then by solving the nonhomogeneous partial differential Equation (4), subject to the dividend payment process (3) and the price positivity condition (5). The authors find that the fundamentals dependency stabilizes bubble dynamics and that stock prices with fundamentals-dependent bubbles can be less volatile than fundamentals. Furthermore, fundamentals-dependent bubbles exhibit various transition patterns, such as nonmonotonic movements and monotonic shrinkage in magnitude and volatility.

\section{4. $W u(1997)$}

The paper estimates a rational stochastic bubble using the Kalman filtering technique. The bubble grows at the discount rate in expectation and it can collapse and restart continuously, allowing for the possibility of a negative bubble. The log of dividends follows a general ARIMA $(p, 1, q)$ process. The model for stock prices with the bubble component, the dividend process and the bubble process are expressed in the state-space form with the bubble being treated as an unobserved state vector. The model parameters are estimated by the method of maximum likelihood and obtain optimal estimates of stochastic bubbles through the Kalman filter.

Consider the standard linear rational expectations model of stock price determination:

$$
\left[E_{t}\left(P_{t+1}+D_{t}\right)-P_{t}\right] / P_{t}=r
$$

where $p$ is the real stock price at time $t, D$ is the real dividend at time $t, E$ is the mathematical expectation conditional on information available at time $t$ and $r$ is the required real rate of return, $r>0$. The log-linear approximation of 
Equation (6) can be written as follows:

$$
q=k+\psi E_{t} p_{t+1}+(1-\psi) d_{t}-p_{t},
$$

where $q$ is the required $\log$ gross return rate, $\Psi$ is average ratio of the stock price to the sum of the stock price and the dividend, $k=-\ln (\Psi)-$ $(1-\Psi) \ln (1 / \Psi-1), p=\ln (P)$, and $d=\ln (D)$.

The general solution to Equation (7) is given by

$$
p_{t}=(k-q) /(1-\psi)+(1-\psi) \sum_{1=0}^{\infty} \psi^{i} E_{t}\left(d_{t+i}\right)+b_{t}=p_{t}^{\mathrm{f}}+b_{t},
$$

where $b_{t}$ satisfies the following homogeneous difference equation:

$$
E_{t}\left(b_{t+i}\right)=(1 / \psi)^{i} b_{t} .
$$

In Equation (7), the no-bubble solution $p$ is exclusively determined by dividends, while $b$ can be driven by events extraneous to the market and is referred to as a rational speculative bubble. After defining the stock price equation, the parametric bubble process and the dividend process in a state-space form, the bubble is treated as an unobserved state vector, which can be estimated by the Kalman filtering technique.

Wu finds statistically significant estimate of the innovation variance for the bubble process. During the bull market of the 1960s, the size of the bubble is 40$50 \%$ of the stock price. Negative bubbles are found during the 1919-1921 bear market, in which case the bubble explains $20-30 \%$ of the decline in stock prices.

\subsection{Wu (1995)}

The model reviewed in the previous Section 3.4 has also been used by the same author to estimate the unobserved nonfundamental component of the exchange rate and to test whether it is significantly different from zero. Using the monetary model of exchange rate determination, the solution for the exchange rate is the sum of two components. The first component, called the fundamental solution, is a function of the observed market fundamental variables. The second component is an unobserved process, which satisfies the monetary model and is called the stochastic bubble. The monetary model, the market fundamental process and the bubble process are expressed in the state-space form, with the bubble being treated as a state variable. The Kalman filter can then be used to estimate the state variable.

The author finds no significant estimate of a bubble component during the period 1974-1988. Similar results were obtained for the subsample, 
1981-1985, during which the US dollar appreciated most drastically and a bubble might have occurred.

Sections 5-7 elaborate our extensions of the five key papers reviewed in this section. The added advantage of our methodological innovation is that it allows us to test for possible linkages between national bubbles. Section 4 describes the rationale for searching for linkages between national bubbles.

\section{Global Stock Market Integration}

Once bubbles are confirmed empirically in the four mature stock markets, we proceed to test linkages between these markets in terms of these nonfundamental components. In this context, we adopt a subset VAR methodology presented in Lutkepohl (1993, p. 179). The approach builds into it the causal relations between the series and this gives us the opportunity to analyze the potential global interaction among these national equity markets through the speculative component of the prices. The potential existence of global linkages among equity markets has attracted great interest among scholars because of its impact on global diversification.

During the past 30 years, world stock markets have become more integrated, primarily because of financial deregulation and advances in computer technology. Financial researchers have examined various aspects of the evolution of this particular aspect of world integration. In analyzing the results of such studies, one could deduce that greater global integration implies lesser benefits from international portfolio diversification. If this is true, how can one explain the ever-increasing flow of big sums of money invested in international markets? To put differently, while Tesar and Werner (1992) confirm the home bias in the globalization of stock markets, why are increasing amounts of funds invested in nonhome equity markets?

The analysis of the October 19, 1987 stock market crash may offer some insight in answering this question. Roll (1988, 1989), King and Wadhwani (1990), Hamao, Musulis, and Ng (1990), and Malliaris and Urrutia (1992) confirm that almost all stock markets fell together during the October 1987 crash despite the existing differences of the national economies while no significant interrelationships seem to exist for periods prior and post the crash. Malliaris and Urrutia (1997) also confirm the simultaneous fall of national stock market returns because of the Iraqi invasion of Kuwait in July 1990. This evidence supports the hypothesis that certain global events, such as the 
crash of October 1987 or the invasion of Kuwait in July 1990, tend to move world equity markets in the same direction, thus reducing the effectiveness of international diversification. On the other hand, in the absence of global events, national markets are dominated by domestic fundamentals, and international investing increases the benefits of diversification. Exceptions exist, as in the case of regional markets, such as the European stock markets reported in Malliaris and Urrutia (1996).

A review of the literature on linkages among international stock markets can be found in McCarthy and Najand (1995). These authors adopt the state space methodology to infer the linkage relationships between the stock markets in Canada, Germany, Japan, UK, and the US. The authors claim that this approach not only determines the causal relationship, in the Granger sense, but it delivers the result with minimum number of parameters necessary. They report that the US market exerts the most influence on other markets. Since these authors use daily data, there is some overlap in the market trading time and they attempt to take care of that in the interpretation of their results. The main finding is consistent with similar findings by other researchers, such as, Eun and Shim (1989), who examine nine stock markets in the North America and Europe over period 1980-1985 in a VAR framework.

From this rapid review of global stock market integration, it becomes apparent that the topic of linkages between bubbles has not been addressed. Our methodology for testing the existence of bubbles in national markets has the additional advantage that it renders itself for also testing for possible linkages between bubbles in these mature stock markets. We augment our contribution to the literature by exploring this issue also.

\section{Our Methodological Contribution}

The purpose of our study is to search empirically for fundamental and nonfundamental components in the national stock markets of the US, Japan, Germany, and the UK, using a state-of-the-art econometric methodology. The word nonfundamental or bubble in this context implies the deviation of the observed stock price from the fundamental part driven by the dividend process. Once this nonfundamental part is estimated we investigate how this might be traveling between these four markets.

We focus on the postwar period in these four countries as opposed to the authors reviewed in the previous section who concentrate on only the US. 
All data are monthly returns of the S\&P 500, Nikkei 225, Dax-30, and FT-100 indexes ranging from January 1951 to December 1998, that is, 576 observations. All data are converted to real values using the corresponding CPI measures and Global Financial Data provided the data. In order to establish the soundness of our methodology we have reproduced the results from Wu (1997) using annual US data (also obtained from Global Financial Data) covering the period 1871-1998. These results are available in Bhar and Malliaris (2001).

Since the nonfundamental part is not observed, the modeling problem is necessarily that of a partially observed system. Wu (1997) employs a similar concept but our implementation is quite different as described in Bhar and Malliaris (2001). We follow Shumway and Stoffer (2000, p. 306) to develop a Dynamic Linear Model, DLM, to treat both the dividend process and the nonfundamental process as part of the unobserved components, the state vector. These states are filtered out of the observations that include the observed dividend and the price, which form the measurement vector.

We also establish the superior performance of our stock price model with a nonfundamental component compared to the simple stock price model with a GARCH error. Our modeling approach makes this comparison straightforward within the same maximum likelihood framework. Wu (1997) does not report any model adequacy tests and the precise moment conditions needed in the GMM estimation are not reported either. On the other hand, our models are subjected to a battery of diagnostic tests applicable to partially observed state space systems. Since Bhar and Malliaris (2001) describe the details of the models we adopt, in Sections 6 and 7 we only outline briefly the essential elements of our approach. In Section 8, we describe the procedure for testing the propagation of the nonfundamental parts between the four countries.

\section{Dynamic Linear Model with Nonfundamental Component}

Our starting point is Equations (8) and (9) described earlier. As our preliminary investigations reveal that both the log real price and log real dividend series are nonstationary, we choose to work with the first differenced series. Thus, Equation (8) becomes,

$$
\Delta p_{t}=\Delta p_{t}^{\mathrm{f}}+\Delta b_{t}
$$

where $\Delta p_{t}^{\mathrm{f}} \equiv(1-\psi) \sum_{i=0}^{\infty} \psi^{i} E_{t}\left(d_{t+i}\right)-(1-\psi) \sum_{i=0}^{\infty} \psi^{i} E_{t-1}\left(d_{t-1+i}\right)$. Assume the parametric representation of Equation (9) is

$$
b_{t+1}=\frac{1}{\psi} b_{t}+\varepsilon_{\eta}, \quad \varepsilon_{\eta}: N\left(0, \sigma_{\eta}^{2}\right),
$$




$$
\Delta b_{t}=\frac{1}{\psi}\left(b_{t}-b_{t-1}\right) .
$$

In order to express the fundamental component of the price, $\Delta p_{t}^{\mathrm{f}}$, in terms of the dividend process, we fit an appropriate AR model of sufficient order so that the Akaike information criterion, AIC, is minimized. We find that for the Japanese data a AR(1) model is sufficient whereas for the other three countries we need AR(3) models. The infinite sums in the expression for $\Delta p_{t}^{\mathrm{f}}$ may be expressed in terms of the parameters of the dividend process once we note the following conditions. First, the differenced log real dividend series is stationary, therefore the infinite sum converges. Second, any finite order AR process can be expressed in companion form (VAR of order 1) by using extended state variables, i.e., suitable lags of the original variables (Campbell, Lo, and MacKinlay, 1997, p. 280). And third, using demeaned variables the VAR(1) process can be easily used for multiperiod ahead forecast (Campbell, Lo, and MacKinlay, 1997, p. 280).

Assuming the demeaned log real dividend process has the following AR(3) representation,

$$
\Delta d_{t}=\phi_{1} \Delta d_{t-1}+\phi_{2} \Delta d_{t-2}+\phi_{3} \Delta d_{t-3}+\varepsilon_{\delta}, \quad \varepsilon_{\delta}: N\left(0, \sigma_{\delta}^{2}\right)
$$

the companion form may be written as,

$$
\begin{aligned}
{\left[\begin{array}{c}
\Delta d_{t} \\
\Delta d_{t-1} \\
\Delta d_{t-2}
\end{array}\right] } & =\left[\begin{array}{ccc}
\phi_{1} & \phi_{2} & \phi_{3} \\
1 & 0 & 0 \\
0 & 1 & 0
\end{array}\right]\left[\begin{array}{c}
\Delta d_{t-1} \\
\Delta d_{t-2} \\
\Delta d_{t-3}
\end{array}\right]+\left[\begin{array}{c}
\varepsilon_{\delta} \\
0 \\
0
\end{array}\right] \\
\text { or } \quad X_{t} & =\Phi X_{t-1}+\Xi_{t},
\end{aligned}
$$

where the definitions of $X_{t}, \Phi$, and $\Xi_{t}$ are obvious from comparison of Equations (9) and (10). Following Campbell, Lo, and MacKinlay (1997, p. 280), $\Delta p_{t}^{\mathrm{f}}$ may be expressed as (with $I$ being the identity matrix of the same dimension as $\Phi)$

$$
\Delta p_{t}^{\mathrm{f}}=\Delta d_{t}+\psi \Phi(I-\psi \Phi)^{-1} \Delta X_{t}
$$

We can now express Equation (5) in terms of the fundamental component and the bubble component,

$$
\Delta p_{t}=\Delta d_{t}+e^{\prime} \psi \Phi(I-\psi \Phi)^{-1} \Delta X_{t}+\Delta b_{t}
$$

where $e^{\prime} \equiv\left[\begin{array}{lll}1 & 0 & 0\end{array}\right]$ 
Equations (12), (14), and (17) can now be set up as a DLM and this is shown in Appendix A. The details of the estimation procedure of such a DLM are described in Appendix C.

\section{Dynamic Linear Model with Garch Error}

In order to compare the performance of the model discussed in the previous section, we develop the DLM for a model without the nonfundamental component. We maintain the same framework so that a comparison can be more meaningful. This is in contrast to the approach taken by Wu (1997), where the nobubble solution was estimated in the GMM framework. We also note that the model should account for the stylized fact of correlations in the variance of the stock return series. This is done by incorporating the $\operatorname{GARCH}(1,1)$ effect in the price equation (17) without the bubble component. In this context we adopt the methodology of Harvey, Ruiz, and Sentana (1992) and follow Kim and Nelson (1999, p. 144) to suitably augment the state vector of the DLM so that the time varying conditional variance could be accounted for.

In essence, the price difference equation (17) should now become,

$$
\begin{aligned}
\Delta p_{t} & =\Delta d_{t}+e^{\prime} \psi \Phi(I-\psi \Phi)^{-1} \Delta X_{t}+\varepsilon_{p, t}, \\
\varepsilon_{p, t} & \sim N\left(0, h_{t}\right), \quad h_{t}=\alpha_{0}+\alpha_{1} \varepsilon_{p, t-1}^{2}+\beta_{1} h_{t-1} .
\end{aligned}
$$

In order to set up the DLM in this case of Garch error together with dynamic of the dividend process, we include the details in Appendix B. Section 8 takes up the issues in modeling the linkages between the markets in the subset VAR framework.

\section{Subset VAR Framework for Establishing Linkages Between Markets}

The methodology developed in this paper allows us to decompose the stock prices in their fundamental and the nonfundamental components. We, analyze the linkage relationship both through the fundamental as well as through the speculative component. This helps us to understand whether the market linkages are through the fundamental or through the speculative components of the price series. Also, since we are dealing with monthly data, the time overlap problem between markets is largely nonexistent.

The econometric procedure we adopt is referred to as the subset VAR. Use of standard VAR approach to study causal relations between variables is frequently 
employed. A typical VAR model involves a large number of coefficients to be estimated and thus estimation uncertainty remains. Some of the coefficients may in fact be zero. When we impose zero constraints on the coefficients in full VAR estimation problem what results is the subset VAR. But, since most often no priori knowledge is available that will guide us to constrain certain coefficients, we base the modeling strategy on information provided by the AIC (Akaike Information Criterion) and the HQ (Hannan-Quinn) model selection criteria. Actual mathematical definitions and the details of this approach can be found in Lutkepohl (1993, Ch. 5). Below, we describe this procedure very briefly.

We first obtain the order of the VAR process for the four variables using the information criterion mentioned above. The top-down strategy starts from this full VAR model and the coefficients are deleted one at a time (from the highest lag term) from the four equations separately. Each time a coefficient is deleted, the model is estimated using least-squares algorithm and the information criterion is compared with the previous minimum one. If the current value of the criterion is greater than the previous minimum value, the coefficient is maintained otherwise it is deleted. The process is repeated for each of the four equations in the system. Once all the zero restrictions are determined the final set of equations are estimated again which gives the most parsimonious model. We also check for the adequacy of this model by examining the multivariate version of the portmanteau test for whiteness of the residuals as suggested by Lutkepohl (1993, p. 188). Once the subset VAR model is estimated there is no further need for testing causal relations and/or linkages between the variables. The causality testing is built into the model development process. Therefore, we examine linkages between the four markets in our study using this subset VAR model.

As mentioned earlier, we explore linkages between these markets in two stages. In the first stage, the fundamental price series are all found to be stationary, and hence in this case the modeling is done using the levels of the variables. We find evidence of one unit root in the speculative components of the price series for all the four markets. As we suspect existence of a cointegrating relation between these speculative components, we explore this using Johansen's cointegration test and find evidence of one cointegrating vector. It is, therefore, natural to estimate a vector error correction model, which is essentially a restricted VAR model with the cointegrating relation designed into it. As suggested in Lutkepohl (1993, p. 378), we examine the causal relation between these variables in the same way as for a stable system. In other 
words, we explore the linkages as for the fundamental price component but in this case we use first differenced form and use the lagged values of the cointegrating vector as well.

\section{Discussion of Results}

We analyze the monthly data, covering the postwar period, for the four mature stock markets of Germany, Japan, UK, and the US. In Table 1, we present the estimation results of the nonfundamental component solutions. It is clear that most of the parameters are statistically significant. The discount parameter, $\psi$, is close to the respective sample values while the significant $\sigma_{\eta}$ for all the four countries imply highly variable speculative components. The estimated parameters of the dividend processes are close to their respective univariate estimation (not reported here) results. As is evident from Table 2, the significant ARCH and the Garch parameters indicate appropriateness of the error specification for the log price difference series for the models with no speculative components. There is substantial persistence in the variance process.

Next, we analyze the residual diagnostics in order to ascertain the appropriateness of the model (Table 3 ) for the monthly data series for all four countries. We find evidence of whiteness on residuals from the portmanteau test and the

Table 1. Parameter estimates from the state space model using Kalman filter nonfundamental solution for monthly data.

\begin{tabular}{lcrrrrr}
\hline & $\psi$ & $\sigma_{\eta}$ & \multicolumn{1}{c}{$\phi_{1}$} & \multicolumn{1}{c}{$\phi_{2}$} & \multicolumn{1}{c}{$\phi_{3}$} & \multicolumn{1}{c}{$\sigma_{\delta}$} \\
\hline Germany & $0.9980^{*}$ & $0.0470^{*}$ & -0.0009 & $0.0611^{*}$ & $0.0947^{*}$ & $0.0475^{*}$ \\
& $(0.0011)$ & $(0.0010)$ & $(0.0400)$ & $(0.0210)$ & $(0.0271)$ & $(0.0002)$ \\
\multirow{2}{*}{ Japan } & $0.9989^{*}$ & $0.0570^{*}$ & $-0.0879^{*}$ & & & $0.0511^{*}$ \\
& $(0.0010)$ & $(0.0013)$ & $(0.0370)$ & & & $(0.0007)$ \\
UK & $0.9983^{*}$ & $0.0535^{*}$ & $-0.5210^{*}$ & $-0.3669^{*}$ & $-0.1324^{*}$ & $0.0407^{*}$ \\
& $(0.0047)$ & $(0.0009)$ & $(0.0144)$ & $(0.0214)$ & $(0.0225)$ & $(0.0003)$ \\
USA & $0.9964^{*}$ & $0.0416^{*}$ & $-0.7218^{*}$ & $-0.3553^{*}$ & $-0.0969^{*}$ & $0.0287^{*}$ \\
& $(0.0020)$ & $(0.0009)$ & $(0.0350)$ & $(0.0453)$ & $(0.0387)$ & $(0.0007)$ \\
\hline
\end{tabular}

Estimates reported here are obtained from maximizing the innovation form of the likelihood function. Numerical optimization procedure in GAUSS is used without any parameter restriction. The standard errors (reported below the parameters in parentheses) are obtained from the Hessian matrix at the point of convergence. These estimates are robust to different starting values including different specification of the prior covariance matrix. Significance at $5 \%$ level is indicated by *. 
Table 2. Parameter estimates from the state space model using Kalman filter GARCH $(1,1)$ error for price equation: monthly data.

\begin{tabular}{lcccccccc}
\hline & $\psi$ & $\phi_{1}$ & $\phi_{2}$ & $\phi_{3}$ & $\sigma_{\delta}$ & $\alpha_{0}$ & $\alpha_{1}$ & $\beta_{1}$ \\
\hline Germany & $0.8526^{*}$ & 0.0047 & 0.0631 & $0.0848^{*}$ & $0.0475^{*}$ & $0.0001^{*}$ & $0.1108^{*}$ & $0.8633^{*}$ \\
& $(0.0391)$ & $(0.0407)$ & $(0.0409)$ & $(0.0415)$ & $(0.0014)$ & $(5.14 \mathrm{e}-5)$ & $(0.0299)$ & $(0.0341)$ \\
Japan & $0.5437^{*}$ & $-0.0906^{*}$ & & & $0.0511^{*}$ & 0.0000 & $0.0988^{*}$ & $0.8869^{*}$ \\
& $(0.0372)$ & $(0.0407)$ & & & $(0.0015)$ & $(0.0000)$ & $(0.0232)$ & $(0.0301)$ \\
UK & $0.2830^{*}$ & $-0.5331^{*}$ & $-0.3425^{*}$ & $-0.1148^{*}$ & $0.0407^{*}$ & $0.0004^{*}$ & $0.2307^{*}$ & $0.6107^{*}$ \\
& $(0.0380)$ & $(0.0411)$ & $(0.0440)$ & $(0.0399)$ & $(0.0012)$ & $(0.0001)$ & $(0.0541)$ & $(0.0910)$ \\
USA & $0.3189^{*}$ & $-0.7213^{*}$ & $-0.3271^{*}$ & $-0.0901^{*}$ & $0.0288^{*}$ & $0.0001^{*}$ & $0.0657^{*}$ & $0.8365^{*}$ \\
& $(0.0344)$ & $(0.0413)$ & $(0.0484)$ & $(0.0400)$ & $(0.0008)$ & $(4.62 \mathrm{e}-5)$ & $(0.0274)$ & $(0.0533)$ \\
\hline
\end{tabular}

Estimates reported here are obtained from maximizing the innovation form of the likelihood function. Numerical optimization procedure in GAUSS is used without any parameter restriction. The standard errors (reported below the parameters in parentheses) are obtained from the Hessian matrix at the point of convergence. These estimates are robust to different starting values including different specification of the prior covariance matrix. GARCH $(1,1)$ error for state space system implemented following Harvey, Ruiz, and Sentana (1992). Significance at $5 \%$ level is indicated by *.

Table 3. Residual diagnostics and model adequacy tests: monthly data.

\begin{tabular}{|c|c|c|c|c|c|}
\hline & Portmanteau & $\mathrm{ARCH}$ & KS test & MNR & Recursive $T$ \\
\hline \multicolumn{6}{|c|}{ Nonfundamental solution } \\
\hline Germany & 0.253 & 0.158 & 0.176 & 0.586 & 0.903 \\
\hline Japan & 0.061 & 0.206 & 0.093 & 0.379 & 0.972 \\
\hline UK & 0.366 & 0.199 & 0.136 & 0.467 & 0.931 \\
\hline USA & 0.377 & 0.327 & 0.048 & 0.425 & 0.894 \\
\hline \multicolumn{6}{|c|}{ With GARCH $(1,1)$ error } \\
\hline Germany & 0.254 & 0.195 & 0.175 & 0.466 & 0.806 \\
\hline Japan & 0.017 & 0.194 & 0.089 & 0.186 & 0.771 \\
\hline UK & 0.307 & 0.179 & 0.139 & 0.571 & 0.907 \\
\hline USA & 0.353 & 0.283 & 0.047 & 0.418 & 0.846 \\
\hline
\end{tabular}

Entries are $p$-values for the respective statistics except for the KS statistic. These diagnostics are computed from the recursive residual of the measurement equation, which corresponds to the real dividend process. The null hypothesis in portmanteau test is that the residuals are serially uncorrelated. The ARCH test checks for no serial correlations in the squared residual up to lag 26. Both these test are applicable to recursive residuals as explained in Wells (1996, p. 27). MNR is the modified Von Neumann ratio test using recursive residual for model adequacy (see Harvey, 1990, Ch. 5). Similarly, if the model is correctly specified then Recursive $T$ has a Student's $t$-distribution (see Harvey, 1990, p. 157). KS statistic represents the KolmogorovSmirnov test statistic for normality. 95 and 99\% significance levels in this test are 0.057 and 0.068 , respectively. When KS statistic is less than 0.057 or 0.068 the null hypothesis of normality cannot be rejected at the indicated level of significance. 
lack of ARCH effect in the residuals from ARCH test results. The US data also support the normality of the residuals. More importantly, however, the tests for model adequacy are captured by the von-Neumann ratio and the recursive t-test. As pointed out in Harvey (1990, p. 157), the von-Neumann test provides the most appropriate basis for a general test of misspecification with recursive residuals. In this context, the dynamic linear models for both the approaches perform extremely well.

Figure 1 plots the nonfundamental price ratio for the sample period and the substantial variation of the speculative component is visible for all the countries. Except for the US, there is evidence of negative component for the other three countries in the initial part of the sample period. Each country was affected differently by the oil price shock of the 1970s. The most severe impact appears to have occurred in the UK. The fall in the speculative percentage during the October 1987 stock market crash is evident for all countries. It is also worth

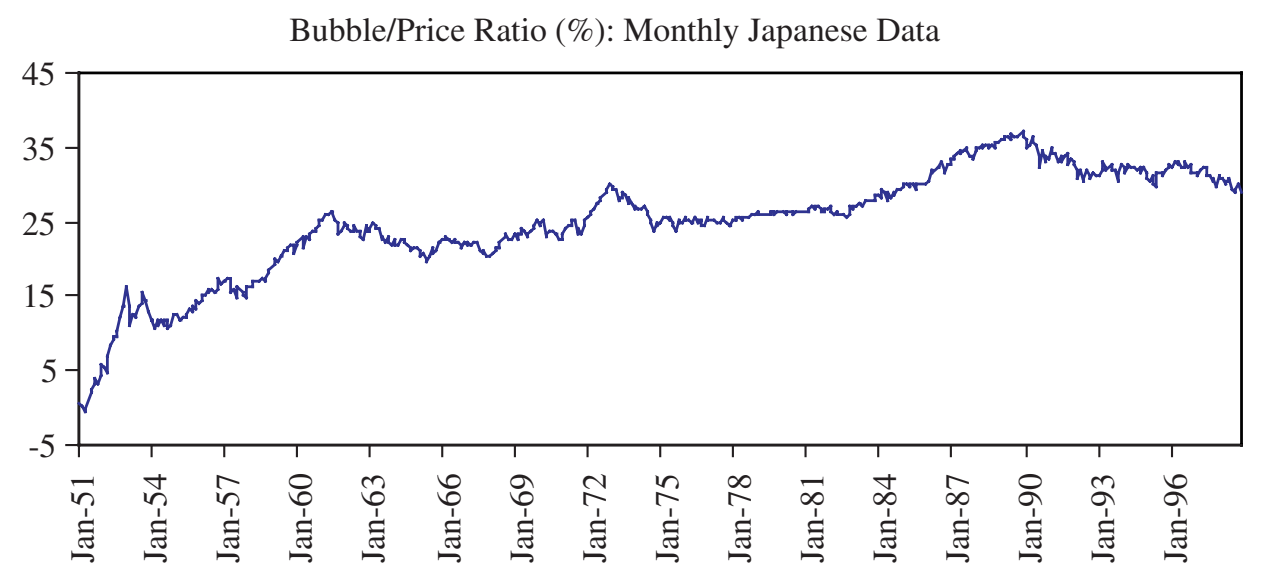

Bubble/Price Ratio (\%): Monthly US Data

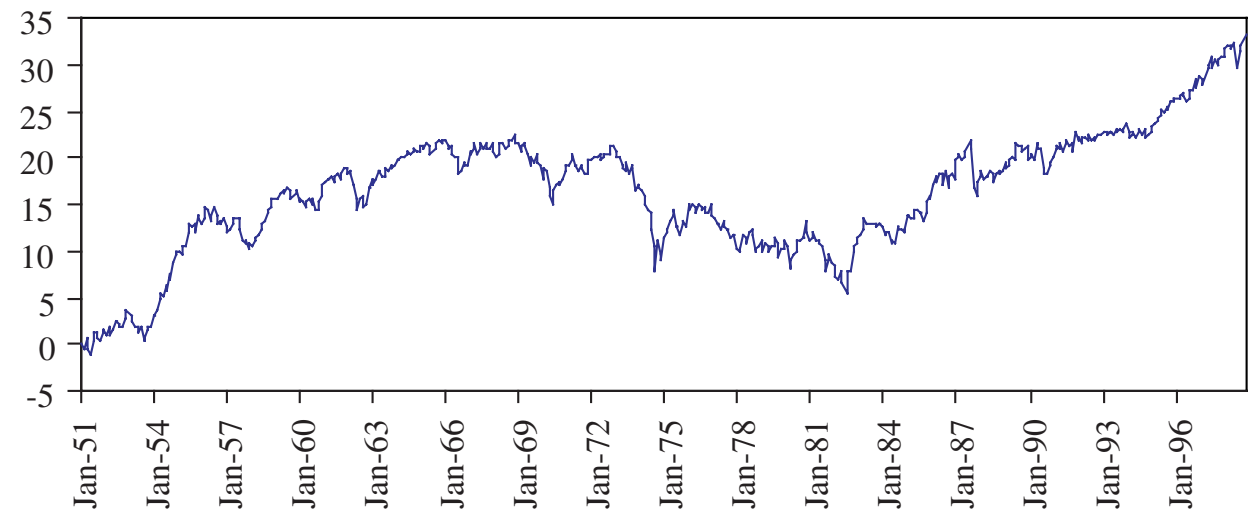

Figure 1. Plots using the smoothed estimates of the nonfundamental component from the state space model monthly data for Japan and USA. 


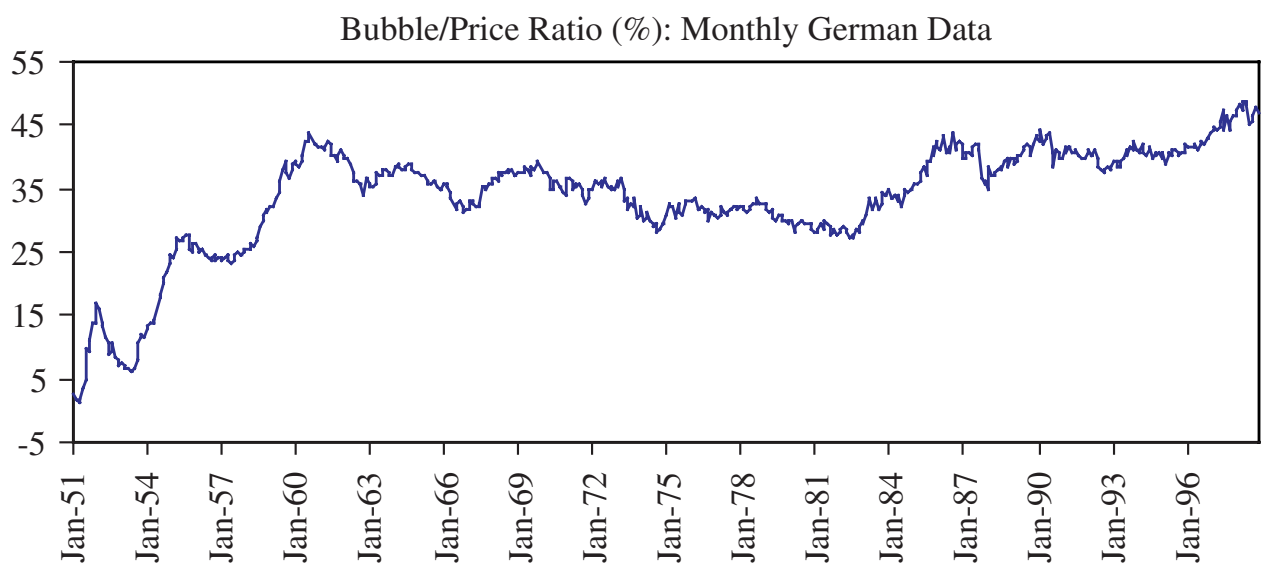

Bubble/Price Ratio (\%): Monthly UK Data

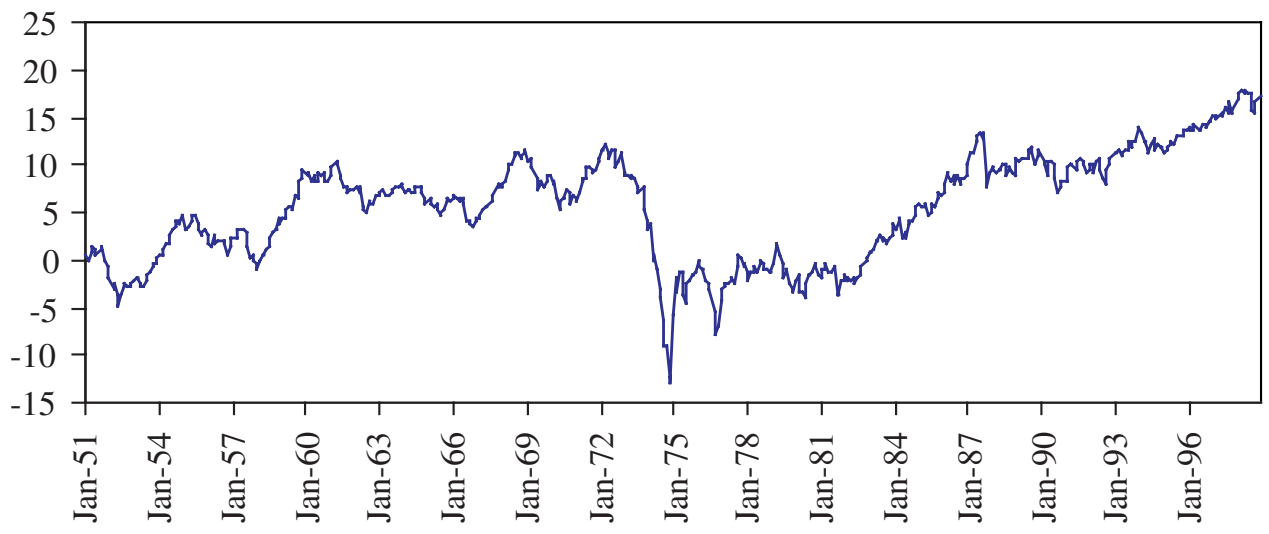

Figure 2. Plots using the smoothed estimates of the nonfundamental component from the state space model monthly data for Germany and UK.

observing that there is a general upward trend for the nonfundamental price ratio toward the later part of sample period for Germany, UK, and the US but not for Japan. The figures also provide the visual evidence of the collapsing and self-starting nature of the stochastic nonfundamental component we have attempted to capture in this study.

In order to quantify the performance improvement of the nonfundamental solution compared to the case with GARCH $(1,1)$ errors, we present in Table 4 the in sample fitting statistics, RMSE and MAE.

These criteria are defined as,

$$
\mathrm{RMSE}=\frac{1}{T} \sum_{t=1}^{T}\left(\hat{p}_{t}-p_{t}\right)^{2}, \quad \mathrm{MAE}=\frac{1}{T} \sum_{t=1}^{T}\left|\hat{p}_{t}-p_{t}\right|,
$$

where $\hat{p}_{t}$ is the fitted price and $T$ is the number of observations. The entries in Table 4 confirm that the nonfundamental component solution does a credible 
Table 4. Nonfundamental solution versus solution with GARCH error compared monthly data.

\begin{tabular}{lcc}
\hline & RMSE & MAE \\
\hline Nonfundamental solution & & \\
Germany & 0.796 & 0.795 \\
Japan & 1.730 & 1.730 \\
UK & 0.247 & 0.366 \\
USA & 0.117 & 0.895 \\
With GARCH (1,1) error & & \\
Germany & 2.945 & 2.945 \\
Japan & 4.394 & 4.395 \\
UK & 0.719 & 0.838 \\
USA & 1.734 & 1.735 \\
\hline
\end{tabular}

RMSE and MAE stand for "root mean squared error" and "mean absolute error", respectively. These are computed from the differences between the actual log prices and the fitted log prices from the corresponding estimated model. Additional details are in the text.

job in terms of both metrics. For example, in the case of US the metric RMSE is reduced to $7 \%$ and the metric MAE to $52 \%$ of the solution with Garch error, respectively.

We indicated earlier the importance and the extent of investigation into the study of market linkages by various researchers. In this paper, we are able to focus on this aspect in two different levels. The study of stochastic bubbles through the dynamic linear models enables us to decompose the price into a fundamental and a bubble component. It is, therefore, natural to examine whether the market linkages exist via both these components. McCarthy and Najand (1995) demonstrated the influence of the US market on several other OECD countries using daily data which might have unintended consequences of trading time overlap in these markets. Using monthly data over a period of 48 years, we are in a better position to analyze the market interrelationships.

VAR methodology is often employed to study causal relationships. If some variables are not Granger-causal for the others, then zero coefficients are obtained. Besides, the information in the data may not be sufficient to provide precise estimates of the coefficients. In this context the top-down strategy of the subset VAR approach described in the earlier section is most suitable. For the fundamental price series we adopt this approach in the levels of the variables since these are all found to be stationary. Using the Hannan-Quinn criterion, 
we start our VAR model with a lag of one and follow the subset analysis process described before. This gives us the model presented in Table 5. As with McCarthy and Najand (1995) we find strong evidence of the US dominance on all the other three countries, but no reverse causality. This is a particularly important finding in the sense that this causality exists in the fundamental components of the prices. Intuitively, this evidence suggests that the US economy, as represented by the stock market data, acts as the engine of global growth. For Germany and Japan, the causality from the US is significant at the 5\% level whereas for the UK it is significant at the $1 \%$ level only. The overall significance of this modeling approach is also established by testing the multivariate version of the portmanteau test to detect whiteness of the residuals.

We also apply the top-down strategy for the subset VAR approach to the nonfundamental components to examine the causality between the four markets. Since the nonfundamental components are found to be nonstationary (results for the unit root tests not included), we model this using the first difference of the log prices. With the nonstationary speculative price series it is natural to expect some long-term equilibrium relationship between these variables. We detected one cointegrating vector using Johansen's procedure and this has been described in Table 6. We follow the same procedure (as for the fundamental prices) to obtain the subset VAR model, including the cointegrating vector that

Table 5. Subset VAR estimation results for linkages between markets in fundamental prices.

\begin{tabular}{|c|c|c|c|c|c|}
\hline & $\mathrm{GR}(-1)$ & $\mathrm{JP}(-1)$ & $\mathrm{UK}(-1)$ & US $(-1)$ & Constant \\
\hline Germany & $\begin{array}{l}0.2074^{*} \\
(3.40)\end{array}$ & & & $\begin{array}{l}0.1904^{*} \\
(3.89)\end{array}$ & $\begin{array}{l}1.7063^{*} \\
(8.23)\end{array}$ \\
\hline Japan & $\begin{array}{l}-0.1029 \\
(-1.91)\end{array}$ & & & $\begin{array}{l}0.1878^{*} \\
(3.08)\end{array}$ & $\begin{array}{l}6.1837^{*} \\
(23.95)\end{array}$ \\
\hline UK & & & $\begin{array}{l}0.0939^{*} \\
(1.97)\end{array}$ & $\begin{array}{l}0.1078 * * \\
(1.76)\end{array}$ & $\begin{array}{l}5.0729^{*} \\
(18.02)\end{array}$ \\
\hline US & & & & & $\begin{array}{l}4.4358^{*} \\
(25.50)\end{array}$ \\
\hline
\end{tabular}

Details of the methodology for determining the subset VAR relations are given in the text. This has been done in the level variables since the fundamental price series are stationary. The numbers in parentheses are $t$-statistics for the corresponding coefficient. Significance at 5 and $10 \%$ level are indicated by $*$ and ${ }^{* *}$, respectively. The $p$-value for the multivariate portmanteau statistic for residual white noise is 0.017. This is described in Lutkepohl (1993, p. 188). This indicates that the model adequately represents the relationship documented here. 
Table 6. Subset VAR estimation results for linkages between markets in nonfundamental prices.

\begin{tabular}{|c|c|c|c|c|c|c|}
\hline & $\Delta \mathrm{GR}(-1)$ & $\Delta \mathrm{JP}(-1)$ & $\Delta \mathrm{UK}(-1)$ & $\Delta \mathrm{US}(-1)$ & Coint $(-1)$ & Constant \\
\hline$\Delta$ Germany & $\begin{array}{l}0.1289^{*} \\
(2.94)\end{array}$ & & & $\begin{array}{l}0.1904^{*} \\
(3.91)\end{array}$ & $\begin{array}{l}0.0071^{*} \\
(2.47)\end{array}$ & $\begin{array}{l}0.0033 \\
(1.74)\end{array}$ \\
\hline$\Delta$ Japan & $\begin{array}{l}-0.1436^{*} \\
(-2.67)\end{array}$ & & & $\begin{array}{l}0.1915^{*} \\
(3.20)\end{array}$ & $\begin{array}{l}0.0167^{*} \\
(4.76)\end{array}$ & $\begin{array}{l}0.0048^{*} \\
(2.09)\end{array}$ \\
\hline$\Delta \mathrm{UK}$ & & & $\begin{array}{l}0.0956^{*} \\
(1.99)\end{array}$ & $\begin{array}{l}0.1064 * * \\
(1.73)\end{array}$ & & $\begin{array}{l}0.0016 \\
(0.74)\end{array}$ \\
\hline$\Delta \mathrm{US}$ & & & & & $\begin{array}{l}0.0009^{*} \\
(3.57)\end{array}$ & $\begin{array}{l}0.0038^{*} \\
(2.21)\end{array}$ \\
\hline
\end{tabular}

The nonfundamental prices are found nonstationary and Johansen's procedure identified existence of one cointegrating vector. The lagged value of this cointegrating vector (COINT) has been used in estimating the subset VAR relations for the linkages between the markets. The details of the unit root and the cointegration tests are not reported here but can be obtained from the authors. The estimated cointegrating vector (normalized on GR) including TREND and constant terms is given below. The numbers in parentheses are $t$-statistics for the corresponding coefficient. Significance at 5 and $10 \%$ levels are indicated by $*$ and $* *$, respectively.

GR $(-1)-1.5826 \mathrm{JP}(-1)+2.7303 \mathrm{UK}(-1)-3.2545 \mathrm{US}(-1)+0.0054$ TREND + 2.3772

The $p$-value for the multivariate portmanteau statistic for residual white noise is 0.068 . This is described in Lutkepohl (1993, p. 188). This indicates that the model adequately represents the relationship documented here.

describes the causal relationship between these markets. Table 6 shows that causality exists from the US to the other three markets. Also, these linkages are significant at the 5\% level for Germany and Japan and only at the $1 \%$ level for the UK. Similar to the fundamental prices, there is no reverse causality in the speculative price components as well. It is also observed that the strength of this causality from the US to Japan is slightly stronger for the speculative price process, 0.1915 as opposed to 0.1878 for the fundamental prices.

It is also noted from Table 6 that the coefficients of the error correction term i.e. "Coint $(-1)$ " are statistically significant. This implies that the modeled variables i.e. the changes in log prices, adjust to departures from the equilibrium relationship. The magnitude of the coefficient "Coint $(-1)$ " for the Japanese log price difference is much higher than the others, capturing, first the upward and later, the downward trend in the Japanese market. Although, the existence of an error correction model implies some form of forecasting ability, we do not pursue this in this paper. Finally, we note the multivariate portmanteau test 
for whiteness of residuals in Table 6. This again supports the model adequacy and hence the inferences drawn are statistically meaningful.

\section{Conclusions}

Economists have long conjectured that movements in stock prices may involve speculative bubbles because trading often generates over-priced or under-priced markets. A speculative bubble is usually defined as the difference between the market value of a security and its fundamental value. Although there are several important theoretical issues surrounding the topic of asset bubbles, the existence of bubbles is inherently an empirical issue that has not yet been settled.

This paper reviews several important tests and offers a new methodology that improves upon the existing ones. In particular, we implement the state space form in such a way that it treats both the dividend process and the nonfundamental process as part of the state vector in a dynamic linear model that allows for a straightforward comparison with the model that only allows GARCH errors. The new methodology is applied to the four mature markets of the US, Japan, England, and Germany to test whether a nonfundamental component was present during the period of January 1951 to December 1998. To establish the soundness of our methodology, we have also applied a battery of diagnostic tests. Our methodology establishes that asset prices in the US, Japan, UK, and Germany have deviated from fundamentals during our sample period. These deviations we call "rational bubbles" or "speculative nonfundamental components".

Once we find evidence of nonfundamental components in these four mature stock markets, we next ask the question whether these are interrelated. We avoid using the technical term of contagion because it has a very specific meaning. Several authors use contagion to mean a significant increase in cross-market linkages, usually after a major shock. For example, when the Thai economy experienced a major devaluation of its currency during the summer of 1997, the spreading of the crisis across several Asian countries has been viewed as a contagion. Unlike the short-term cross-market linkages that emerge as a result of a major, often regional economic shock, we are interested in this paper in long-run linkages. Speculative effects often take long time, that is several years to develop and one is interested in knowing if such processes travel from one mature economy to another. Our statistical tests of the long-term linkages between the four mature stock markets provide evidence that the US stock 
market nonfundamental component or bubble causes a bubble in the other three markets but we find no evidence for reverse causality. Thus, in contrast to numerous studies showing that these four mature stock markets are cointegrated, our decomposition of the national markets returns into fundamental and nonfundamental components offers the additional insight that it is the US nonfundamental component that statistically causes the emergence of bubbles in Japan, Germany and the UK. Such evidence suggests that global diversification can be more effective if the US stock market becomes more successful in reducing the emergence of bubbles at home.

\section{Appendix A: Setting up the DLM with Nonfundamental Component}

Equation (17) in the main text represents the measurement equation of the DLM and we need to suitably define the state equation for the model. An examination of Equations (12) and (14) suggests that the following state equation represent the dynamics of the dividend and the nonfundamental process:

$$
\begin{aligned}
{\left[\begin{array}{c}
\Delta d_{t} \\
\Delta d_{t-1} \\
\Delta d_{t-2} \\
\Delta d_{t-3} \\
b_{t} \\
b_{t-1}
\end{array}\right]=} & {\left[\begin{array}{cccccc}
\phi_{1} & \phi_{2} & \phi_{3} & 0 & 0 & 0 \\
1 & 0 & 0 & 0 & 0 & 0 \\
0 & 1 & 0 & 0 & 0 & 0 \\
0 & 0 & 1 & 0 & 0 & 0 \\
0 & 0 & 0 & 0 & \frac{1}{\psi} & 0 \\
0 & 0 & 0 & 0 & 1 & 0
\end{array}\right]\left[\begin{array}{c}
\Delta d_{t-1} \\
\Delta d_{t-2} \\
\Delta d_{t-3} \\
\Delta d_{t-4} \\
b_{t-1} \\
b_{t-2}
\end{array}\right]+\left[\begin{array}{c}
\varepsilon_{\delta} \\
0 \\
0 \\
0 \\
\varepsilon_{\eta} \\
0
\end{array}\right], } \\
& \left(\begin{array}{c}
\varepsilon_{\delta} \\
\varepsilon_{\eta}
\end{array}\right): N\left(\left[\begin{array}{l}
0 \\
0
\end{array}\right],\left[\begin{array}{cc}
\sigma_{\delta}^{2} & 0 \\
0 & \sigma_{\eta}^{2}
\end{array}\right]\right) .
\end{aligned}
$$

We are in a position now to define the measurement equation of the DLM in terms of the state vector in Equation (A.1). This is achieved by examining Equation (17) and defining a row vector, $M \equiv e^{\prime} \psi \Phi(I-\psi \Phi)^{-1}=\left[m_{1}, m_{2}, m_{3}\right]$, as follows:

$$
\Delta p_{t}=\Delta d_{t}+\left[m_{1}, m_{2}, m_{3}\right]\left[\begin{array}{c}
\Delta d_{t}-\Delta d_{t-1} \\
\Delta d_{t-1}-\Delta d_{t-2} \\
\Delta d_{t-2}-\Delta d_{t-3}
\end{array}\right]+\Delta b_{t},
$$


or

$$
\begin{aligned}
{\left[\begin{array}{c}
\Delta p_{t} \\
\Delta d_{t}
\end{array}\right]=} & {\left[\begin{array}{cccccc}
\left(1+m_{1}\right) & \left(m_{2}-m_{1}\right) & \left(m_{3}-m_{2}\right) & -m_{3} & 1 & -1 \\
1 & 0 & 0 & 0 & 0 & 0
\end{array}\right] } \\
& \times\left[\begin{array}{c}
\Delta d_{t} \\
\Delta d_{t-1} \\
\Delta d_{t-2} \\
\Delta d_{t-3} \\
b_{t} \\
b_{t-1}
\end{array}\right]
\end{aligned}
$$

Equation (A.3) determines the measurement equation of the DLM without any measurement error. In other words, the evolution of the state vector in Equation (A.1) results in the measurement of the measurement vector through Equation (A.3). Equations (A.1) and (A.3) represent the DLM for the model with nonfundamental component when the dividend process is described by the AR(3) system in Equation (14). In our sample this is the case for Germany, UK, and the US. Since the data for Japan required only an AR(1) process for the dividend in Equation (14), the DLM, in this case, may be written directly as:

$$
\begin{gathered}
{\left[\begin{array}{c}
\Delta d_{t} \\
\Delta d_{t-1} \\
b_{t} \\
b_{t-1}
\end{array}\right]=\left[\begin{array}{cccc}
\phi_{1} & 0 & 0 & 0 \\
1 & 0 & 0 & 0 \\
0 & 0 & \frac{1}{\psi} & 0 \\
0 & 0 & 1 & 0
\end{array}\right]\left[\begin{array}{c}
\Delta d_{t-1} \\
\Delta d_{t-2} \\
b_{t-1} \\
b_{t-2}
\end{array}\right]+\left[\begin{array}{c}
\varepsilon_{\delta} \\
0 \\
\varepsilon_{\eta} \\
0
\end{array}\right],} \\
\left(\begin{array}{c}
\varepsilon_{\delta} \\
\varepsilon_{\eta}
\end{array}\right): N\left(\left[\begin{array}{l}
0 \\
0
\end{array}\right],\left[\begin{array}{cc}
\sigma_{\delta}^{2} & 0 \\
0 & \sigma_{\eta}^{2}
\end{array}\right]\right) .
\end{gathered}
$$

Similarly, the measurement equation for the DLM of the solution with nonfundamental component for the Japanese data becomes,

$$
\left[\begin{array}{c}
\Delta p_{t} \\
\Delta d_{t}
\end{array}\right]=\left[\begin{array}{cccc}
\left(1+m_{1}\right) & -m_{1} & 1 & -1 \\
1 & 0 & 0 & 0
\end{array}\right]\left[\begin{array}{c}
\Delta d_{t} \\
\Delta d_{t-1} \\
b_{t} \\
b_{t-1}
\end{array}\right],
$$

where $M \equiv e^{\prime} \psi \Phi(I-\psi \Phi)^{-1}=\left[m_{1}\right]$, since $e^{\prime}=[1], \Phi=\left[\phi_{1}\right]$. 
We have now completed the DLM for the solutions with nonfundamental component for all the four markets in our sample. The parameters of the models, embedded in these equations, may be estimated by maximum likelihood method as described in Appendix C. At the same time both the filtered and the smoothed estimates of the nonfundamental component series are inferred from the observed price and the dividend series.

\section{Appendix B: Setting up the DLM with Garch Error}

For Germany, UK and the USA with AR(3) representation of the dividend change process, the state equation with $\operatorname{GARCH}(1,1)$ error becomes,

$$
\begin{gathered}
{\left[\begin{array}{c}
\Delta d_{t} \\
\Delta d_{t-1} \\
\Delta d_{t-2} \\
\Delta d_{t-3} \\
\varepsilon_{p, t}
\end{array}\right]=\left[\begin{array}{ccccc}
\phi_{1} & \phi_{2} & \phi_{3} & 0 & 0 \\
1 & 0 & 0 & 0 & 0 \\
0 & 1 & 0 & 0 & 0 \\
0 & 0 & 1 & 0 & 0 \\
0 & 0 & 0 & 0 & 0
\end{array}\right]\left[\begin{array}{c}
\Delta d_{t-1} \\
\Delta d_{t-2} \\
\Delta d_{t-3} \\
\Delta d_{t-4} \\
\varepsilon_{p, t-1}
\end{array}\right]+\left[\begin{array}{c}
\varepsilon_{\delta} \\
0 \\
0 \\
0 \\
\varepsilon_{p, t}
\end{array}\right],} \\
\left(\begin{array}{c}
\varepsilon_{\delta} \\
\varepsilon_{p, t} \mid \omega_{t-1}
\end{array}\right): N\left(\left[\begin{array}{l}
0 \\
0
\end{array}\right],\left[\begin{array}{cc}
\sigma_{\delta}^{2} & 0 \\
0 & h_{t}
\end{array}\right]\right), \quad h_{t}=\alpha_{0}+\alpha_{1} \varepsilon_{p, t-1}^{2}+\beta_{1} h_{t-1},
\end{gathered}
$$

and $\omega_{t-1}$ is the information set at time $t-1$. This is equivalent to Equation (A.1) in this context. The corresponding measurement equation becomes,

$$
\left[\begin{array}{c}
\Delta p_{t} \\
\Delta d_{t}
\end{array}\right]=\left[\begin{array}{ccccc}
\left(1+m_{1}\right) & \left(m_{2}-m_{1}\right) & \left(m_{3}-m_{2}\right) & -m_{3} & 1 \\
1 & 0 & 0 & 0 & 0
\end{array}\right]\left[\begin{array}{c}
\Delta d_{t} \\
\Delta d_{t-1} \\
\Delta d_{t-2} \\
\Delta d_{t-3} \\
\varepsilon_{p, t}
\end{array}\right] .
$$


For the Japanese data with an AR(1) dividend change process, the DLM may be written following the approach above. The state Equation (B.1) becomes,

$$
\begin{gathered}
{\left[\begin{array}{c}
\Delta d_{t} \\
\Delta d_{t-1} \\
\varepsilon_{p, t}
\end{array}\right]=\left[\begin{array}{ccc}
\phi_{1} & 0 & 0 \\
1 & 0 & 0 \\
0 & 0 & 0
\end{array}\right]\left[\begin{array}{c}
\Delta d_{t} \\
\Delta d_{t-1} \\
\varepsilon_{p, t-1}
\end{array}\right]+\left[\begin{array}{c}
\varepsilon_{\delta} \\
0 \\
\varepsilon_{p, t}
\end{array}\right], \quad(\mathrm{B} .4)} \\
\left(\begin{array}{c}
\varepsilon_{\delta} \\
\varepsilon_{p, t} \mid \omega_{t-1}
\end{array}\right): N\left(\left[\begin{array}{l}
0 \\
0
\end{array}\right], \quad\left[\begin{array}{cc}
\sigma_{\delta}^{2} & 0 \\
0 & h_{t}
\end{array}\right]\right), \quad h_{t}=\alpha_{0}+\alpha_{1} \varepsilon_{p, t-1}^{2}+\beta_{1} h_{t-1} .
\end{gathered}
$$

The corresponding measurement equation becomes,

$$
\left[\begin{array}{c}
\Delta p_{t} \\
\Delta d_{t}
\end{array}\right]=\left[\begin{array}{ccc}
\left(1+m_{1}\right) & -m_{1} & 1 \\
1 & 0 & 0
\end{array}\right]\left[\begin{array}{c}
\Delta d_{t} \\
\Delta d_{t-1} \\
\varepsilon_{p, t}
\end{array}\right] .
$$

In the case of stock price solutions with GARCH error, the parameters to be estimated are those of the dividend process and the $\operatorname{GARCH}(1,1)$ coefficients. The procedure for this is the same as that for the case with nonfundamental component and is described in detail in Appendix $\mathrm{C}$.

\section{Appendix C: Estimating the Parameters of the DLM}

In this appendix, we describe briefly how the unknown parameters in the DLM may be estimated. Our aim is to present an overview of the filtering and smoothing algorithm (known as Kalman filter and smoother) and the optimization of the likelihood function. Before proceeding, however, it is advantageous to express the DLM in term of suitable notations. Since the discussion here is applicable to both the bubble solution and the nobubble solution described earlier, we will not make any distinction between the two once the DLM have been defined.

We consider the DLM with reference to the following state and measurement equations:

$$
\begin{aligned}
& y_{t}=\Gamma y_{t-1}+w_{t} \quad \text { (state equation), } \\
& z_{t}=A_{t} y_{t}+v_{t} \quad \text { (measurement equation). }
\end{aligned}
$$


In this DLM, $y_{t}$ is a $p \times 1$ vector of unobserved state variables, $\Gamma$ is the $p \times p$ state transition matrix governing the evolution of the state vector. $w_{t}$ is the $p \times 1$ vector of independently and identically distributed, zero-mean normal vector with covariance matrix $Q$. The state process is assumed to have started with the initial value given by the vector, $y_{0}$, taken from normally distributed variables with mean vector $\mu_{0}$ and the $p \times p$ covariance matrix, $\Sigma_{0}$.

The state vector itself is not observed but some transformation of these is observed but in a linearly added noisy environment. In this sense, the $q \times 1$ vector $z_{t}$ is observed through the $q \times p$ measurement matrix $A_{t}$ together with the $q \times 1$ Gaussian white noise $v_{t}$, with the covariance matrix, $R$. We also assume that the two noise sources in the state and the measurement equations are uncorrelated.

The next step is to make use of the Gaussian assumptions and produce estimates of the underlying unobserved state vector given the measurements up to a particular point in time. In other words, we would like to find out,

$$
E\left(y_{t} \mid\left\{z_{t-1}, z_{t-2}, \ldots, z_{1}\right\}\right)
$$

and the covariance matrix,

$$
P_{t \mid t-1}=E\left[\left(y_{t}-y_{t \mid t-1}\right)\left(y_{t}-y_{t \mid t-1}\right)^{\prime}\right] .
$$

This is achieved by using Kalman filter and the basic system of equations is described below.

Given the initial conditions $y_{0 \mid 0}=\mu_{0}$, and $P_{0 \mid 0}=\Sigma_{0}$, for observations made at time $1,2,3, \ldots, T$,

$$
\begin{aligned}
y_{t \mid t-1} & =\Gamma y_{t-1 \mid t-1}, \\
P_{t \mid t-1} & =\Gamma P_{t-1 \mid t-1} \Gamma^{\prime}+Q, \\
y_{t \mid t} & =y_{t \mid t-1}+K_{t}\left(z_{t}-A_{t} z_{t \mid t-1}\right),
\end{aligned}
$$

where the Kalman gain matrix

$$
K_{t}=P_{t \mid t-1} A_{t}^{\prime}\left[A_{t} P_{t \mid t-1} A^{\prime}+R\right]^{-1},
$$

and the covariance matrix $P_{t \mid t}$ after the $t$ th measurement has been made is,

$$
P_{t \mid t}=\left[I-K_{t} A_{t}\right] P_{t \mid t-1} \text {. }
$$

Equation (C.3) forecasts the state vector for the next period given the current state vector. Using this one step ahead forecast of the state vector it is possible to define the innovation vector as,

$$
v_{t}=z_{t}-A_{t} y_{t \mid t-1}
$$


and its covariance as,

$$
\Sigma_{t}=A_{t} P_{t \mid t-1} A_{t}^{\prime}+R .
$$

Since in finance and economic applications all the observations are available, it is possible to improve the estimates of state vector based upon the whole sample. This is referred to as Kalman smoother and it starts with initial conditions at the last measurement point i.e., $y_{T \mid T}$ and $P_{T \mid T}$. The following set of equations describes the smoother algorithm:

$$
\begin{aligned}
& y_{t-1 \mid T}=y_{t-1 \mid t-1}+J_{t-1}\left(y_{t \mid T}-y_{t \mid t-1}\right), \\
& P_{t-1 \mid T}=P_{t-1 \mid t-1}+J_{t-1}\left(P_{t \mid T}-P_{t \mid t-1}\right) J_{t-1}^{\prime},
\end{aligned}
$$

where

$$
J_{t-1}=P_{t-1 \mid t-1} \Gamma^{\prime}\left[P_{t \mid t-1}\right]^{-1} .
$$

It should be clear from the above that to implement the smoothing algorithm the quantities $y_{t \mid t}$ and $P_{t \mid t}$ generated during the filter pass must be stored.

With reference to the DLM for the bubble and the nobubble solutions it is obvious that the parameters of interest are embedded in the matrices $\Gamma$ and $Q$, since by construction of our models $R \equiv 0$. The description of the above filtering and the smoothing algorithms assumes that these parameters are known. In fact, we want to determine these parameters and this achieved by maximizing the innovation form of the likelihood function. The one step ahead innovation and its covariance matrix are defined by Equations (C.8) and (C.9) and since these are assumed to be independent and conditionally Gaussian, the $\log$ likelihood function (without the constant term) is given by

$$
\log (L)=-\sum_{t=1}^{T} \log \left|\Sigma_{t}(\Theta)\right|-\sum_{t=1}^{T} v_{t}^{\prime}(\Theta) \Sigma_{t}^{-1}(\Theta) v_{t}(\Theta) .
$$

In this expression, $\Theta$ is specifically used to emphasize the dependence of the $\log$ likelihood function on the parameters of the model. Once the function is maximized with respect to the parameters of the model, the next step of smoothing can start using those estimated parameters.

Maximization of the function in Equation (C.13) may be achieved using one of two approaches. The first one depends on algorithm like Newton-Raphson and the second one is known as the EM (Expectation Maximization) algorithm. In this paper we employ the Newton-Raphson technique to achieve our objective and since the likelihood function is reasonably well behaved, maximization 


\section{Ramaprasad Bhar \& A. G. Malliaris}

is achieved quite quickly. In some modeling situations it may not be so straightforward. EM algorithm has been reported to be quite stable in the presence of bad starting values, although it may take longer to converge. Some researchers report that when good starting values are hard to obtain, a combination of the two approaches may be useful. In that situation it is preferable to employ EM algorithm first in order to obtain an intermediate estimates and then switch to the Newton-Raphson method. Interested readers may refer to Shumway and Stoffer (2000, p. 323).

\section{Acknowledgments}

Current Draft: September 2004. Various earlier versions of this paper were presented at the European Financial Management Association Meetings, Lugano, Switzerland, June 27-30, 2001, at the Western Economic Association Meetings, San Francisco, July 5-8, 2001 and the Seventh Biennial Conference of the Athenian Policy Forum, Frankfurt, Germany, July 28-31, 2004. We are thankful to several discussants and colleagues for their useful suggestions and to two anonymous referees of this journal for their insightful comments that helped us improve our paper.

\section{References}

Bhar, R. and A.G. Malliaris, "Are there Rational Bubbles in the U.S. Stock Market? Overview and a New Test." In George Kaufman (ed.), Asset Price Bubbles: Implications for Monetary and Regulatory Policies, pp. 125-144. Amsterdam: Elsevier (2001).

Binswanger, M. Stock Markets, Speculative Bubbles and Economic Growth, Cheltenham, U.K.: Elgar Publishing (1999).

Blanchard, O.J. and M. Watson, "Bubbles, Rational Expectations and Financial Markets," in P. Wachel, (ed.), Crises in the Economic and Financial Structure, Lexington: Lexington Books (1982).

Blanchard, O.J. and S. Fisher, Lectures on Macroeconomics, Cambridge: MIT Press (1989).

Campbell, J.Y., "Asset Pricing at the Millennium." The Journal of Finance 55, 1515-1568 (2000).

Campbell, J.Y. and R.J. Shiller, "The Dividend-Price Ratio and the Expectations of Future Dividends and Discount Factors." Review of Financial Studies 1, 195-228 (1988a). 
Campbell, J.Y. and R.J. Shiller, "Stock Prices, Earnings and Expected Dividends." Journal of Finance 43, 661-676 (1988b).

Campbell, J.Y., A.W. Lo and A.C. MacKinlay, The Econometrics of Financial Markets. Pinceton: Princeton University Press (1997).

Chirinko, R. and H. Schaller, "Bubbles, Fundamentals, and Investment: A Multiple Equation Testing Strategy." Journal of Monetary Economics 38, 47-76 (1996).

Eun, C. and S. Shim, "International Transmission of Stock Market Movements." Journal of Financial and Quantitative Analysis 24, 241-256 (1989).

Flood, R.P. and P.M. Garber, "Market Fundamentals Versus Price Level Bubbles: The First Tests.” Journal of Political Economy 88, 745-770 (1980).

Hamao, Y., R.W. Masulis and V. Ng, "Correlations in Price Changes and Volatility Across International Stock markets." The Review of Financial Studies 3, 281-307 (1990).

Harvey, A., The Econometric Analysis of Time Series, second edition. Cambridge, Massachusetts: The MIT Press (1990).

Harvey, A., E. Ruiz and E. Sentana, "Unobserved Component Time Series Models with ARCH Disturbances." Journal of Econometrics 52, 129-157 (1992).

Hayford, M. and A.G. Malliaris, "Is the Federal Reserve Stock Market BubbleNeutral?" in George Kaufman (ed.), Asset Price Bubbles: Implications for Monetary and Regulatory Policies, Amsterdam: Elsevier (2001), pp. 229-243.

Ikeda, S. and A. Shibata, "Fundamentals-Dependent Bubbles in Stock Prices." Journal of Monetary Economics 30, 143-168 (1992).

Keynes, J.M., The General Theory of Employment, Interest and Money. London: MacMillan (1936).

Kim, C. and C.R. Nelson, State Space Models with Regime Switching: Classical and Gibbs-Sampling Approach with Applications. Cambridge: The MIT Press (1999).

King, M.A. and S. Wadhwani, "Transmission of Volatility Between Stock Markets." Review of Financial Studies 3, 5-33 (1990).

LeRoy, S. and R.D. Porter, "The Present-Value Relation: Tests Based on Implied Variance Bounds." Econometrica 49, 555-574 (1981).

Lutkepohl, H., Introduction to Multiple Time Series Analysis, second edition. New York: Springer-Verlag (1993).

McCarthy, J. and M. Najand, "State Space Modelling of Linkages Among International Markets." Journal of Multinational Financial Management 5, 1-9 (1995).

Malliaris, A.G. and J.L. Urrutia, “The International Crash of October 1987: Causality

Tests.” Journal of Financial and Quantitative Analysis 27, 353-364 (1992).

Malliaris, A.G. and J.L. Urrutia, "European Stock Market Fluctuations: Short and Long Term Links." Journal of International Financial Markets, Institutions and Money 6, 21-34 (1996). 
Malliaris, A.G. and J.L. Urrutia, "Equity and Oil Markets under External Shocks." in Ghosh, D. and E. Ortiz (eds), Global Structure of Financial Markets, London, U.K.: Routledge Publishers (1997) pp. 103-116.

Roll, R., “The International Crash of October 1987”, in R. Kanphuis, R. Kormendi and H. Watson (eds), Black Monday and the Future of Financial Markets, Homewood, Illinois: Irwin (1988).

Roll, R., "Price Volatility, International Market Links and their Implications for Regulatory Policies." Journal of Financial Services Research 3, 211-236 (1989).

Shiller, R.J., "Do Stock Price Move too Much to be Justified by Subsequent Changes in Dividends.?" American Economic Review 71, 421-436 (1981).

Shumway, R.H. and D.S. Stoffer, Time Series Analysis and Its Applications, New York: Springer (2000).

Tesar, L. and I. Werner, "Home Bias and the Globalization of Securities Markets." National Bureau of Economic Research, Working paper (1992).

West, K.D., "Bubbles, Fads, and Stock Price Volatility Tests: A Partial Evaluation." National Bureau of Economic Research, Working paper (1988).

West, K.D., “A Specification Test for Speculative Bubbles", Quarterly Journal of Economics 102, 553-580 (1987).

Wu, Y., "Are there Rational Bubbles in Foreign Exchange Markets?" Journal of International Money and Finance 14, 27-46 (1995).

Wu, Y., "Rational Bubbles in the Stock Market: Accounting for the U.S. Stock-Price Volatility.” Economic Inquiry 35, 309-319 (1997). 